\title{
Liquid crystal thermography in the diagnosis of scaphoid fractures
}

\author{
K. B. HOSIE, J. WARDROPE, A. C. CROSBY \& D. G. FERGUSON \\ Department of Accident and Emergency Medicine, Royal Hallamshire Hospital, Sheffield, \\ England
}

\section{INTRODUCTION}

Liquid crystal thermography (LCT) is a quick, simple, non-invasive and inexpensive technique. It has been shown to be of use in the diagnosis of stress fractures (Devereaux et al., 1984) and also in the diagnosis of deep venous thrombosis (Cook \& Pilcher, 1974; Sandler \& Martin, 1985). The present authors have assessed the performance of LCT in the diagnosis of scaphoid fractures.

\section{MATERIAL}

LCT consists of pliable latex sheets impregnated with cholestrol crystals which respond to different temperatures by emitting different wavelengths of light ranging from brown (cool) through yellow and green to blue (hot). These latex sheets form one wall of a sealed box with the opposite wall being made of perspex to allow the thermographic image to be viewed. The thermographic detectors are calibrated to react to different temperatures. Each one has a mean temperature and responds $2^{\circ} \mathrm{C}$ above and below this mean. There are eight detectors which respond to mean temperatures of $24,26,28,29$, $30,31,32$ and $33^{\circ} \mathrm{C}$.

Each box is airtight and has a valve through which air can be pumped to make the pliable latex sheet assume a convex contour which can be moulded around the subject under study. The box is held in a frame with a polaroid camera and a flash unit, thus a permanent picture of the thermographic image can be obtained (Novamedix Ltd, Whitchurch, England).

\section{METHOD}

Fifty patients presenting to the Accident and Emergency Department, Royal Hallam-

Correspondence: $\operatorname{Dr}$ K. B. Hosie, c/o Department of Surgery, Leicester Royal Infirmary, Leicester, England. 
Fig. 1 Wire frame mounted on wall with hands positioned to present the anatomical snuff box.

shire Hospital, Sheffield, England, with a clinical diagnosis of fracture of the scaphoid $\overrightarrow{\vec{V}}$ were studied.

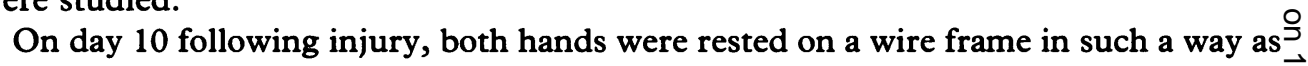
to present the anatomical snuff box. The frame was mounted on a wall to ensurec elevation of the wrists in order to prevent venous pooling (Fig. 1).

After $1 \mathrm{~min}$ the thermographic detector was placed on the wrists and held until an $\overrightarrow{0}$ image formed (Fig. 2). The detectors were changed until the image contained all of these colours indicated by the scale on the side of the detector. This allows the accentuation of any difference in termperature between the two limbs, irrespective of the ambienti temperature.

The assumption is made that fractures are associated with increased vascularity andő that this causes a difference in skin temperature between the injured and uninjured $\stackrel{\mathbb{}}{\circ}$ limb; it is this difference that is detected by LCT. Criteria for the interpretation of thermograms have been described (Cooke and Pilcher, 1974). A thermogram is considered $\frac{3}{5}$ positive if there is a homogenous area of increased temperature in the symptomatic limbo compared with the symptomless limb (Fig. 3a). The scan is negative if there is a symmetrical temperature pattern in the two limbs (Fig. 3b).

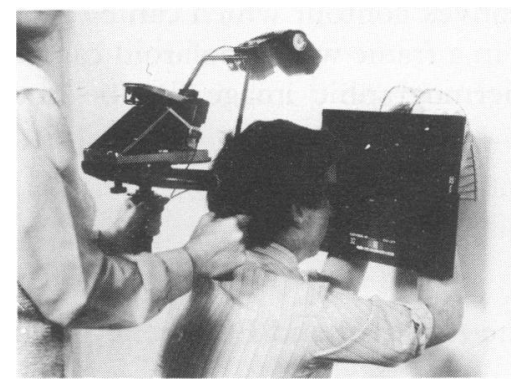

Fig. 2 The equipment in place with the wrists correctly positioned, camera and flash unit mounted for photography. 

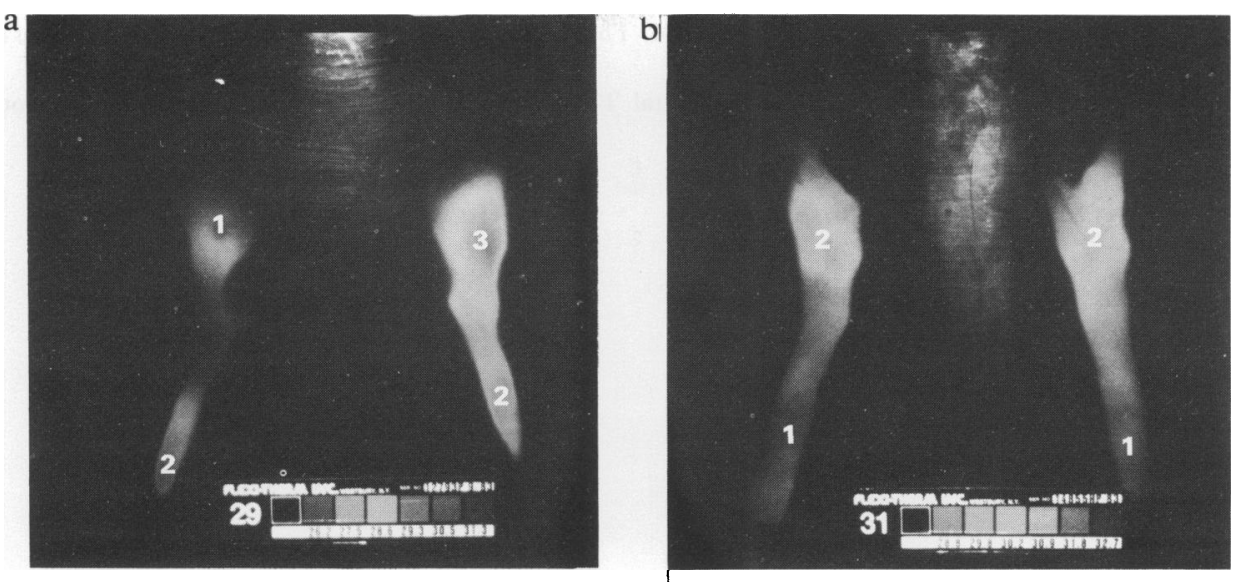

Fig. 3 Polaroid film of scan. The different colours trepresent varying temperatures with brown (1) indicating cooler areas and green (2) and blue (3) hot: (a) shows a positive scan with a hot (blue) area in the region of the anatomical snuff box; (b) shows a negative scan with no difference between the two limbs.

\section{RESULTS}

Comparing LCT with conventional radiology the authors found there were three false negatives giving a sensitivity of $77 \%$ with seven false positive scans giving a specificity of $82 \%$. The overall accuracy was $80 \%$. If the scan is negative, then the negative predictive value is over $90 \%$.

\section{DISCUSSION}

Liquid crystal thermography is a simple, quick and inexpensive technique, costing approximately $£ 4000$ for a complete system.

It is painless, there are no side effects and no exposure to radiation. The technique is non-specific and, as with all non-invasive techniques, has a degree of false positive and false negative results.

However, along with the other uses of LCT, i.e. in DVT (Sandler \& Martin, 1985) and stress fractures (Devereaux et al., 1984), the authors feel this would be a useful piece of equipment in the accident and emergency department.

\section{REFERENCES}

Cook E. D. \& Pilcher M. F. (1974) Deep venous thrombosis preclinical diagnosis by thermography. British fournal of Surgery 61, 971-8. 
Devereaux M. D., Parr G. R. \& Lackman S. M. (1984) The diagnosis of stress fractures in athletes. fournal of $\underset{\mathbb{D}}{\mathrm{T}}$ American Medical Association 252, 531-3.

Sandler D. A. \& Martin J. F. (1985) Liquid Crystal Thermography as a screening test for deep venous thrombosis. Lancet i, 665-8.

Received 20 August 1986; accepted 1 December 1986 